Dear Author,

Please, note that changes made to the HTML content will be added to the article before publication, but are not reflected in this PDF.

Note also that this file should not be used for submitting corrections. 


\section{AUTHOR QUERY FORM}

\begin{tabular}{|c|c|c|}
\hline ELSEVIER & Article Number: 787 & $\begin{array}{l}\text { Please e-mail or fax your responses and any corrections to: } \\
\text { E-mail: corrections.esch@elsevier.tnq.co.in } \\
\text { Fax: }+31204852789\end{array}$ \\
\hline
\end{tabular}

Dear Author,

Please check your proof carefully and mark all corrections at the appropriate place in the proof (e.g., by using on-screen annotation in the PDF file) or compile them in a separate list. Note: if you opt to annotate the file with software other than Adobe Reader then please also highlight the appropriate place in the PDF file. To ensure fast publication of your paper please return your corrections within 48 hours.

For correction or revision of any artwork, please consult http://www.elsevier.com/artworkinstructions.

Any queries or remarks that have arisen during the processing of your manuscript are listed below and highlighted by flags in the proof.

\begin{tabular}{|c|c|}
\hline $\begin{array}{l}\text { Location } \\
\text { in article }\end{array}$ & $\begin{array}{l}\text { Query / Remark: Click on the } Q \text { link to find the query's location in text } \\
\text { Please insert your reply or correction at the corresponding line in the proof }\end{array}$ \\
\hline Q1 & $\begin{array}{l}\text { Please check corresponding author details retained in the corresponding author field and correct if } \\
\text { necessary. }\end{array}$ \\
\hline Q2 & $\begin{array}{l}\text { This section comprises references that occur in the reference list but not in the body of the text. Please cite } \\
\text { each reference in the text or, alternatively, delete it. }\end{array}$ \\
\hline Q3 & Please check the layout of Tables 1 and 3 and correct if necessary. \\
\hline Q4 & Please confirm that given names and surnames have been identified correctly. \\
\hline \multirow[t]{2}{*}{ Q5 } & Please provide the significance for " $* *$ " in table 4. \\
\hline & $\begin{array}{l}\text { Please check this box or indicate } \\
\text { your approval if you have no } \\
\text { corrections to make to the PDF file }\end{array}$ \\
\hline
\end{tabular}

Thank you for your assistance. 


\title{
Factors associated with non-use of condoms in an online community of frequent travellers
}

\author{
${ }^{4}{ }_{L}$ Sami Alcedq*, Stefano Kossuth-Cabrejos, ^Alejandro Piscoyą,

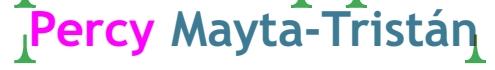

Escuela de Medicina, Universidad Peruana de Ciencias Aplicadas, Lima, Peru

Received 18 December 2013; received in revised form 1 August 2014; accepted 6 October 2014

\author{
KEYWORDS \\ Travel; \\ Unsafe sex; \\ Sexually transmitted \\ diseases; \\ Latin America
}

\begin{abstract}
Summary Background: Millions of travellers around the world have gathered together into online communities. The objective is to analyse the factors associated with risky sexual behaviour among travellers.

Methods: Cross-sectional study was conducted within an online community of travellers using an online survey; we included travellers who had engaged in sexual activity while on their last trip. Risky sexual behaviour was defined as inconsistent condom use $(<100 \%)$, and the factors associated were evaluated using the prevalence ratio (PR).

Results: Of the 468 participants, 245 had sex during their last trip. 59.7\% did not consistently use condoms, and one out of every four participants reported never using condoms. Having a travel destination of Latin America or the Caribbean was significantly associated with inconsistent condom use. This association was maintained (PR 1.37, CI 95\% 1.06-1.77) after adjusting for gender, age, migration, the presence of travel partners, and the use of drugs and alcohol prior to sexual activity.

Conclusion: An association was observed between travel destination (specifically Latin America or the Caribbean) and risky sexual behaviour. For this reason, tourists should be educated in STI transmission and regional STI and HIV incidences both before and during their travels; public health systems ought to work together with travel agencies, international airports, etc., in order to distribute this information and ensure a responsible travel experience.

(c) 2014 Published by Elsevier Ltd.
\end{abstract}

* Corresponding author. Calle Tacna 579 dpto 2, Lima18, Lima, Peru. Tel.: +51 987326826.

E-mail addresses: sami.alcedo@gmail.com (S. Alcedo), 4711929@upc.edu.pe (S. Kossuth-Cabrejos), alepiscoya@gmail.com (A. Piscoya), p.mayta@gmail.com, percy.mayta@upc.edu.pe (P. Mayta-Tristán). 


\section{Introduction}

An undeniable phenomenon in the modern world is the growth and mobility of populations outside of their native countries. In 2013, the World Tourism Organisation (WTO) estimated that the number of tourists reached 1087 million individuals, a figure that represents a $5 \%$ growth from the previous year [1]. One important consequence of this increasingly mobile population is the fact that these individuals can transmit infections in the locations they visit and can spread new infectious diseases or resistant strains of known diseases in their home country [2,3]. Among such diseases, sexually transmitted infections (STIs) are of particular concern due to the fact that almost $50 \%$ of tourists travelling abroad are acquiring new sexual partners and having unprotected sexual intercourse [1,2].

In analysing STI transmission among travellers, the role of risky sexual behaviours in the spread of STIs should not be overlooked [2]. Although there is no consensus definition of risky sexual behaviour, a series of proxy measures have been proposed for measuring risky sexual behaviour. According to several authors, risky sexual behaviour directly depends on the number of sexual partners, condom use, and the use of drugs prior to performing a sexual act [4]; also, the age of first sexual experience [5], and the number of new sexual partners [6] have been reported.

A series of published studies have identified several factors that influence risky sexual behaviour during travel, including travel patterns (e.g., solo travel, travelling with others of the same sex, and short travel time) [7], relationship status during travel and STI/HIV diagnosis in the past 5 years [8], a pre-travel history of multiple partnerships [2], the availability of sexual services in the travel destination [9], and high purchasing power [10]. In regard to this, a question rises on whether travel destination may have a role in the increase of risky sexual behaviour beside other travel characteristics mentioned previously.

Online communities of travellers, such as Couchsurfing, represent important sites for the analysis of risky sexual behaviour because these types of websites attract millions of individuals who frequently travel to numerous destinations across the globe; through these social media websites, they are able to share their experiences (e.g., photos, videos, commentaries, etc.), suggest travel destinations, participate in cultural events and, most importantly, help their fellow members find a place to stay [11], all those may have an influence in their behaviour.

Consequently, the primary objective of the present study is to identify the factors associated with risky sexual behaviour among members of such communities. In particular, the association between travel destination and risky sexual behaviour will be evaluated.

\section{Methods}

\subsection{Design and population}

An analytical cross-sectional study was conducted that examined members of Couchsurfing, an online community of travellers. This online community brings together more than three million travellers from all parts of the world and allows them to seek accommodations from other members of the community during their travels. The Couchsurfing website groups members according to their city of residence, and the current study examined English-speaking members from the most populated cities in North America and Europe who had travelled at least once in the past 12 months. Individuals that were minors were excluded, as were those who did not give informed consent.

\subsection{Sample size}

The Power Analysis and Sample Size (PASS, 2008) program was used to calculate the appropriate sample size. With an alpha of 0.05 and assuming $80 \%$ power, a sample size of 250 was shown to be required to detect an association strength of 2.04 [12] or higher, given the proportion of $41.7 \%$ of affected individuals who were not exposed and $52.9 \%$ who were exposed.

\subsection{Questionnaire and definition of variables}

The response variable was inconsistent condom use during sexual activity. Most studies tend to extend their definition of condom use, for example, a study conducted in South Africa used a score consisting of three items: "always", "sometimes" and "never" [12]. However, given that the World Health Organisation (WHO) has reported that condoms must be used during $100 \%$ of sexual activity to effectively prevent STIs, for the purposes of the current study, inconsistent condom use was defined as condom use at a frequency less than $100 \%$ during sexual activity [4].

To examine the variables related to the use of alcohol and drugs prior to sexual activity, questions were drawn from the Youth Risk Behaviour Survey from the Centers for Disease Control and Prevention (CDC) in the United States $[14,15]$.

The most recent travel destinations of the study participants over the 12 months prior to the study were grouped into the following regions: North America, Africa, Latin America and/or the Caribbean, Europe, Asia, and Oceania. In addition, several other exposure variables were examined, including gender (female/male), age (years), and the use of alcohol and/or drugs (yes/no) prior to sexual activity.

\subsection{Data collection}

The survey was developed using the Survey Monkey program, and a link was generated with the electronic web address. The 20 cities in North America and the 20 cities in Europe with the highest number of Couchsurfing members were selected, and members from these cities were subsequently invited to participate in the study through an advertisement on the main page. The data collection period lasted one month and was conducted between February and March of 2012.

\subsection{Data analysis}

The database was downloaded from the Survey Monkey site in Excel format and was imported into STATA 11.0 for 
Windows following a quality check. Shortly thereafter, the population was described using measures of central tendency (mean and median), distribution (standard deviation (SD), and interquartile range (IQR) for numeric variables. For the categorical variables, the frequencies and percentages were reported. Next, a bivariate analysis was conducted using chi-squared and Fisher's exact tests for the corresponding categorical variables, and the significance level was set at $p<0.05$. The crude and adjusted prevalence ratio $(P R)$ values were calculated with their respective confidence intervals using Poisson regression analysis with robust error variance.

\subsection{Ethical considerations}

This study was approved by the Ethics Committee of the Universidad Peruana de Ciencias Aplicadas (UPC) in Lima, Peru, and permission was granted by the administrators of the Couchsurfing website to conduct the study. Furthermore, the informed consent process was designed to specify that the survey was anonymous and that participation was voluntary. Individuals were only allowed to begin the full survey after they had provided informed consent to participate in the study.

\section{Results}

Of the contacted population of 626 individuals, four refused to participate in the study, seven were eliminated because of their age, and 144 registered participants were excluded for not completing the survey. Thus, the final number of individuals included in the study was 468 (Fig. 1).

With regards to the demographic characteristics of the population, the majority of the study participants $(60.0 \%)$ were women. The mean age was $27 \pm 8.2$ years. In addition, approximately $20 \%$ of the survey respondents reported being bisexual/homosexual. Finally, most participants resided in Europe (57.5\%), while $32.5 \%$ lived in North America.

Regarding travel destinations, $36.54 \%$ of the study participants travelled outside of their region of origin for their most recent trip. The median travel duration was four weeks (IQR 2-12), and the median daily expense was 30 American dollars (IQR 20-70). The majority of survey respondents $(61.1 \%)$ reported being single during the time of their last trip, and $54.5 \%$ travelled for tourism. Approximately one-third (33.6\%) of the study participants selected a private residence for the location of their stay, and $22.4 \%$ were hosted by another Couchsurfing member. Finally, $44.7 \%$ of the participants travelled with companions, and the median number of travel companions was one (IQR 1-2) (Table 1).

Regarding sexual behaviour, approximately half (52.4\%) of the population included in this study had sex during their most recent trip. The median number of sexual partners was one (IQR 1-2). Most travellers (96.8\%) reported having sex with locals or other travellers, while only $3.2 \%$ engaged in sexual activity with sex workers. The median number of sexual encounters reported during this most recent trip was three (IQR 1-8.8), and $10.6 \%$ of all sexual encounters were homosexual.

With regards to risky sexual behaviour, the majority of the population $(59.7 \%)$ did not practice consistent condom use during their most recent trip. Specifically, one out of every four participants reported never having used a condom during their sexual encounters. Moreover, the majority $(61.7 \%)$ of survey respondents reported having consumed alcohol before engaging in sexual activity. However, the majority of participants $(60.4 \%)$ reported being sober on the occasions in which they engaged in sex. With regards to drug use, a large majority (85.4\%) confirmed not having used any type of drug prior to their sexual encounters. Of the population that reported having used drugs prior to sex (14.6\%), most (63.6\%) reported using cannabis (Table 2).

Table 3 shows the results of the bivariate analysis. This analysis established that travelling alone, travelling with a partner, and travelling to Latin America or the Caribbean were statistically associated $(p<0.05)$ with inconsistent condom use during sexual activity. No significant associations were observed $(p>0.05)$ for the variables of sex, age, city of origin, reason for travel, accommodation, sexual orientation, duration of travel, daily travel expenses,

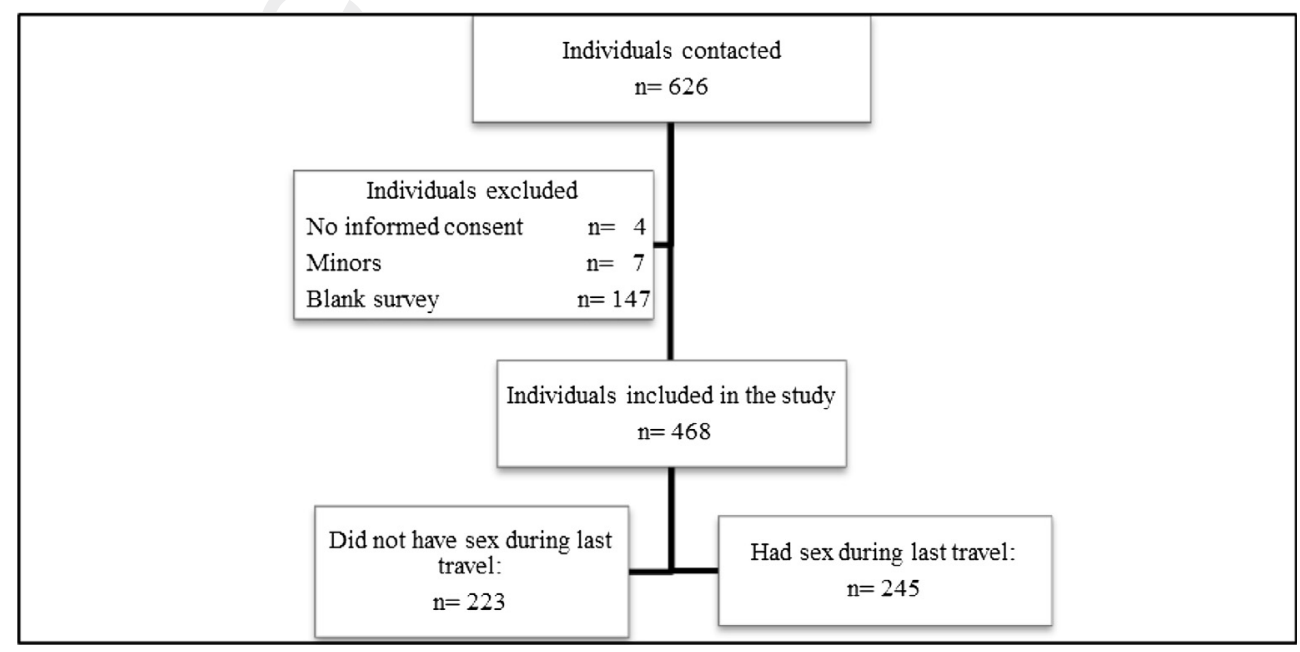

Figure 1 Flowchart of population study. 
Table 1 Demographic characteristics and characteristics of the most recent travel destination among an online Q3 community of travellers $(n=468)$.

\begin{tabular}{|c|c|}
\hline Variables & $n^{\mathrm{a}}(\%)$ \\
\hline \multicolumn{2}{|l|}{ Demographic characteristics } \\
\hline Male & $187(40.0)$ \\
\hline Age (Mean, SD) & $27.6( \pm 8.2)$ \\
\hline In a relationship & $174(37.2)$ \\
\hline \multicolumn{2}{|l|}{ Sexual orientation } \\
\hline Heterosexual & $375(80.8)$ \\
\hline Bisexual & $62(13.4)$ \\
\hline Homosexual & $27(5.8)$ \\
\hline \multicolumn{2}{|l|}{ Place of residency } \\
\hline Europe & $265(57.5)$ \\
\hline North America & $150(32.5)$ \\
\hline Asia & $25(5.4)$ \\
\hline America or the Caribbean & $16(3.5)$ \\
\hline Oceania & $4(0.9)$ \\
\hline Africa & $1(0.2)$ \\
\hline \multicolumn{2}{|l|}{ Characteristics of the last point of travel } \\
\hline \multicolumn{2}{|l|}{ Destination } \\
\hline Europe & $276(59.7)$ \\
\hline North America & $83(18.0)$ \\
\hline Latin America or the Caribbean & $47(10.2)$ \\
\hline Asia & $39(8.4)$ \\
\hline Africa & $11(2.4)$ \\
\hline Oceania & $6(1.3)$ \\
\hline \multicolumn{2}{|l|}{ Reason for Travel } \\
\hline Tourism & $255(54.5)$ \\
\hline Visiting family & $55(11.8)$ \\
\hline Business & $49(10.5)$ \\
\hline Other & $109(23.3)$ \\
\hline \multicolumn{2}{|l|}{ Accommodations } \\
\hline Hotel/Hostel & $173(36.9)$ \\
\hline Private residence & $157(33.6)$ \\
\hline Couchsurfing member & $105(22.4)$ \\
\hline Other & $31(7.0)$ \\
\hline Travelled outside region of residency & $167(36.5)$ \\
\hline Travelled alone & $259(55.3)$ \\
\hline Duration of travel in weeks (median, IQR) & $4(2-12)$ \\
\hline Daily expenses (US) (median, IQR) & $30(20-70)$ \\
\hline $\begin{array}{l}\text { Number of travel companions } \\
\text { (median, IQR) }\end{array}$ & $1(1-2)$ \\
\hline
\end{tabular}

homosexual encounters, or the consumption of alcohol and/or drugs prior to sexual activity.

The results of the multivariate analysis are shown in Table 4. After adjusting for sex, age, migration, and the use of alcohol and/or drugs, having travelled to Latin America or the Caribbean was shown to be significantly associated with an increased risk of inconsistent condom use (PR: 1.37; 95\% Cl 1.06-1.77).

\section{Discussion}

The current results reveal that nearly $60 \%$ of individuals who engaged in sex during their last travel did not consistently use condoms. The present study demonstrates that
Table 2 Characteristics of sexual behaviour during the last point of travel among members of an online community of travellers ( $n=245)$.

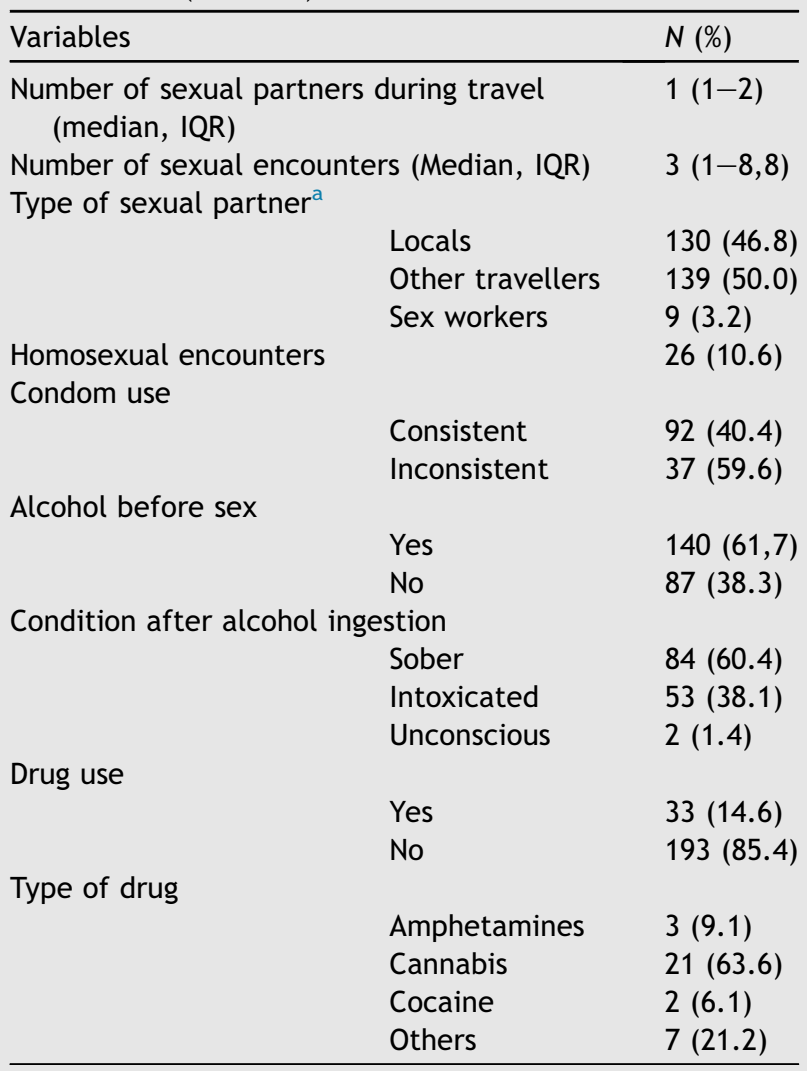

a This question is multiple choice.

travel to Latin America or the Caribbean was associated with a $44 \%$ increase in the prevalence of not using condoms in all sexual encounters, even after adjusting for the variables of sex, age, travel outside of the region of origin, and the use of alcohol and/or drugs prior to sexual activity. The results of multivariate analysis also revealed that travelling with a partner increases the rate of inconsistent condom use, which might be expected given that the risk of STI transmission is lower for individuals in a stable relationship; in a study analysing the dynamics of condom use in heterosexual males in Thailand, it was determined that being married and being in a long relationship (over 90 days) were both associated with decreased use of condoms [16].

According to the WHO, the efficacy of condoms to decrease STIs requires that condoms be used consistently [4]. Numerous studies have reported the rate of condom use in the general population. For example, Brazil's Ministry of Health found that $63 \%$ of men and $69 \%$ of women reported using a condom during their last sexual encounter [18]. Nonetheless, beyond simply reporting the rate of condom use in the general population, it is important to identify populations at high risk for contracting STIs, especially during situations associated with an increased risk of acquiring STIs, such as while travelling $[17,19,20]$.

A cross-sectional study of travellers in Hong Kong reported a frequency of inconsistent condom use of $53 \%$ when examining the most recent travel experience within the 
Table 3 Variables associated with inconsistent condom use during sexual encounters at the last point of travel.

\begin{tabular}{|c|c|c|c|}
\hline \multirow[t]{2}{*}{ Variable } & $\begin{array}{l}\text { Inconsistent } \\
\text { condom use } \\
(n=136)\end{array}$ & $\begin{array}{l}\text { Consistent } \\
\text { condom use } \\
(n=92)\end{array}$ & \multirow[t]{2}{*}{$p$} \\
\hline & $n(\%)$ & $n(\%)$ & \\
\hline \multicolumn{4}{|l|}{$\operatorname{Sex}^{a}$} \\
\hline Male & $61(57.6)$ & $45(42.5)$ & \multirow[t]{2}{*}{0.546} \\
\hline Female & $75(61.5)$ & $47(38.5)$ & \\
\hline \multicolumn{4}{|l|}{ Origin ${ }^{\mathrm{b}}$} \\
\hline North America & $51(68.0)$ & $24(32.0)$ & \multirow[t]{5}{*}{0.148} \\
\hline Europe & $66(54.6)$ & $55(45,5)$ & \\
\hline $\begin{array}{l}\text { Latin America/ } \\
\text { Caribbean }\end{array}$ & $7(77.8)$ & $2(22.2)$ & \\
\hline Asia & $9(64.3)$ & $5(35.7)$ & \\
\hline Oceania & $1(25.0)$ & $3(75.0)$ & \\
\hline \multicolumn{4}{|c|}{ Destination: Latin America or the Caribbean ${ }^{a}$} \\
\hline Yes & $23(82.1)$ & $5(17.9)$ & \multirow[t]{2}{*}{0.011} \\
\hline No & $112(56.9)$ & $85(43.2)$ & \\
\hline \multicolumn{4}{|c|}{ Travel outside region of origin ${ }^{a}$} \\
\hline Yes & $58(62.4)$ & $35(37.6)$ & \multirow[t]{2}{*}{0.572} \\
\hline No & $75(58.6)$ & $53(41.4)$ & \\
\hline \multicolumn{4}{|l|}{ Reason for travel $^{\mathrm{b}}$} \\
\hline Business & $8(38.1)$ & $13(61.9)$ & \multirow[t]{4}{*}{0.081} \\
\hline Tourism & $73(58.4)$ & $52(41.6)$ & \\
\hline Visiting family & $18(75.0)$ & $6(25.0)$ & \\
\hline Other & $37(63.8)$ & $21(36.2)$ & \\
\hline \multicolumn{4}{|c|}{ Sexual Orientation ${ }^{\mathrm{b}}$} \\
\hline Heterosexual & $105(57.7)$ & $77(42.3)$ & \multirow[t]{3}{*}{0.445} \\
\hline Bisexual & $21(70.0)$ & $9(30.0)$ & \\
\hline Homosexual & $9(60.0)$ & $6(40.0)$ & \\
\hline \multicolumn{4}{|c|}{ Person with whom travelled ${ }^{a}$} \\
\hline Solo & $61(46.9)$ & $69(53.1)$ & \multirow[t]{3}{*}{0.020} \\
\hline Friends & $24(60.0)$ & $16(40.0)$ & \\
\hline Partner & $43(74.1)$ & $15(25.9)$ & \\
\hline \multicolumn{4}{|c|}{ Homosexual Encounters ${ }^{a}$} \\
\hline Yes & $15(57.7)$ & $11(42.3)$ & \multirow[t]{2}{*}{0.829} \\
\hline No & $121(59.9)$ & $81(40.1)$ & \\
\hline \multicolumn{4}{|c|}{ Hosted by a Couchsurfing member } \\
\hline Yes & $26(50.0)$ & $26(50.0)$ & \multirow[t]{2}{*}{0.106} \\
\hline No & $110(62.5)$ & $66(37.5)$ & \\
\hline
\end{tabular}

past 12 months [19]. This study of travellers in Hong Kong is quite similar to the current study in terms of the population characteristics and the primary findings, which are largely consistent with our results. However, another crosssectional study conducted with travellers (backpackers) in Australia reported a frequency of inconsistent condom use of $78 \%$, which is higher than that observed in the present study [21]. In contrast, a cross-sectional study of a sample of 45 travellers returning from tropical destinations reported that none of the participants practised consistent condom use (40\% confirmed irregular use, and $60 \%$ never used condoms). However, this finding is likely due to the smaller sample size than the previously cited studies $[19,21,22]$.

A cross-sectional study was conducted using a selfadministered survey with a sample of 2540 travellers who had visited the city of Cuzco, Peru. They reported a $69.3 \%$ rate of consistent condom use, although $93.4 \%$ of the participants had previously responded on the survey that they had planned to use a condom in the event of sexual activity [23]. This difference obligates us to reflect on the factors that affect consistent condom use, especially in the present study, in which a statistically significant association was observed between consistent condom use and the selection of Latin America or the Caribbean as a travel destination.

Based on a review of the literature, this association could be due to the great majority of travellers only being knowledgeable about the high prevalence of HIV infections that result from casual sexual encounters of tourists in other parts of the world (i.e., Sub-Saharan Africa, Southeast Asia, and India) [24]. If, in fact, they underestimate the possibility of contracting STIs in Latin America, travellers might be expected to be more likely to use a condom in regions of the world where they know HIV rates to be highly prevalent.

Recently, several studies have been published regarding the risks encountered by volunteers who travel as part of international social projects. These studies have shown that volunteers who travel to participate in social projects in Latin America and the Caribbean showed a higher frequency of new sexual partners than those who travelled to other destinations [25]. According to the authors, this was due to the local attitudes about sexuality, as well as the knowledge of the transmission of HIV and other STIs in Africa and Asia. For instance, in a communication given to the British general public in 2012, the British HIV Association reported that 15\% of all new HIV infections between 2002 and 2010 were produced abroad, with the most common

Table 4 Factors associated with condom use in an online community of travellers who had sex during their most recent trip.

\begin{tabular}{|c|c|c|c|c|}
\hline \multirow[t]{2}{*}{ Variables } & \multicolumn{2}{|l|}{ Crude $^{a}$} & \multicolumn{2}{|l|}{ Adjusted $^{* *}$} \\
\hline & PR $(95 \% \mathrm{Cl})$ & $p$ & PR $(95 \% \mathrm{Cl})$ & $p$ \\
\hline Destination Latin America or the Caribbean & $1.44(1.17-1.79)$ & 0.001 & $1.37(1.06-1.77)$ & 0.016 \\
\hline \multicolumn{5}{|l|}{ Person with whom travelled } \\
\hline With partner & $1.40(1.12-1.74)$ & 0.003 & $1.43(1.11-1.84)$ & 0.006 \\
\hline With friends & $1.13(0.84-1.53)$ & 0.425 & $1.13(0.84-1.53)$ & 0.410 \\
\hline Alone & 1.00 & & 1.00 & \\
\hline
\end{tabular}

a Adjusted for gender, age, migration, use of alcohol and drugs. 
S. Alcedo et al.

locations being Thailand and South Africa, popular travel destinations in both Asia and Africa respectively [26].

Another important finding of the current study involved the consumption of alcohol and/or other drugs prior to sexual activity. Regarding the consumption of alcohol, three out of every five individuals who had sex during their most recent trip reported having ingested alcohol before sex. However, only $40 \%$ confirmed being intoxicated as a consequence of said ingestion. With regards to drug use, approximately $15 \%$ reported having used drugs before sex. It is fitting to highlight the fact that both of these behaviours have been described in the literature as factors associated with risky sexual behaviour and STI transmission $[4,27]$.

\subsection{Limitations}

This study has several limitations. First, because this is a cross-sectional study, it cannot be used to establish causal relationships. However, our results are similar to those of other cross-sectional studies with larger sample sizes $[19,21]$. We recommend conducting additional studies in the future to evaluate other factors, such as the intrinsic sexual behaviour of each individual. Because we did not have access to a list of community members, we decided to use a non probabilistic sample.

Also, given that the members of CouchSurfing may not represent the average traveller, our results are not generalizable to tourists engaging in unprotected sex abroad.

Regarding potential bias, there is a possibility of recall bias because of the fact that the variables were studied retrospectively. For this reason, we decided to limit the interval of variables to the most recent travel experience within the past 12 months. In addition, social desirability bias may have played a role because of the fact that the survey dealt with the sensitive topic of human sexuality. Nonetheless, the risk of this type of bias is minimised by the fact that the survey was anonymous and self-administered.

\section{Conclusion}

Despite its limitations, this study identified an association between travel destination, in this case Latin America or the Caribbean, and risky sexual behaviour. This result is consistent with previous studies reported in the literature. For this reason, tourists should be educated in STI transmission and regional STI and HIV incidences both before and during their travels; public health systems ought to work together with travel agencies, international airports, etc., in order to distribute this information and ensure a responsible travel experience.

\section{Funding}

None.

\section{Conflict of interest}

None.

\section{Uncited reference}

[13].

\section{Acknowledgements}

We thank Dr. Antonio Bernabé-Ortiz for making revisions to the manuscript during the writing process.

\section{References}

[1] World Tourism Organization (UNWTO) [Internet]. Beijing: United Nations; 2001. Available at: http://mkt.unwto.org/ en/content/tourism-highlights [updated may 2014; cited on July 2, 2014].

[2] Vivancos R, Abubakar I, Hunter PR. Foreign travel, casual sex and sexually transmitted infections: a systematic review and meta-analysis. Int J Infect Dis 2010;14:e842-51.

[3] Ward BJ, Plourde P. Travel and sexually transmitted infections. J Travel Med 2006;13(5):300-17.

[4] Apostolopoulos Y, Sönmez S, Yu CH. HIV-risk behaviours of American spring break vacationers: a case of situational disinhibition? Int J STD AIDS 2002;13(11):733-43.

[5] Vivancos R, Abubakar I, Hunter PR. Foreign travel associated with increased sexual risk-taking, alcohol and drug use among UK university students: a cohort study. Int J STD AIDS 2010; 21(1):46-51.

[6] Salit IE, Sano M, Boggild AK, Kain KC. Travel patterns and risk behaviour of HIV-positive people travelling internationally. CMAJ 2005;172(7):884-8.

[7] Hawkes S, Hart GJ, Johnson AM, Shergold C, Ross E, Herbert KM, et al. Risk behaviour and HIV prevalence in international travellers. AIDS 1994;8(2):247-52.

[8] Mercer CH, Fenton KA, Welling K, Copas AJ, Erens B, Johnson AM. Sexual partner acquisition while overseas: results from a British national probability survey. Sex Transm Infect 2007;83:517-22. http://dx.doi.org/10.1136/sti.2007.026377.

[9] Abdullah AS, Fielding R, Hedley AJ, Luk YK. Risk factors for sexually transmitted diseases and casual sex among Chinese patients attending government sexually transmitted disease clinics in Hong Kong. Sex Transm Dis 2002;29(6):360-5.

[10] Tveit KS, Nilsen A, Nyfors A. Casual sexual experience abroad in patients attending an STI clinic and at high risk for HIV infection. Genitourin Med 1994;70(1):12-4.

[11] Xiang Z, Gretzel U. Role of social media in online travel information search. Tour Manag 2010;31:179-88.

[12] Nyembezi A, Ruiter RA, Van den Borne B, Sifunda S, Funani I, Reddy P. Correlates of consistent condom use among recently initiated and traditionally circumcised men in the rural areas of the Eastern Cape Province, South Africa. BMC Public Health 2014; 14:668.

[13] Cabada MM, Echevarria JI, Seas C, Gotuzzo E. High prevalence of sexually transmitted infections among young Peruvians who have sexual intercourse with foreign travelers in Cuzco. J Travel Med 2009;16(5):299-303.

[14] Center for Disease Control \& Prevention (CDC) [Internet]. Youth risk behavior surveillance system. Atlanta. 1991 [accessed 13.04.12; cited April 17, 2012]. Available at:, http://www.cdc.gov/HealthyYouth/yrbs/index.htm.

[15] Brener ND, Kann L, McMannus T, Kinchen SA, Sundberg EC, Ross JG. Reliability of the 1999 youth risk behavior survey questionnaire. J Adolesce Health 2002;31(4):336-42.

[16] Chamratrithirong A, Kaiser P. The dynamics of condom use with regular and casual partners: analysis of the 2006 national sexual behavior survey of Thailand. PLOS ONE 2012;7(7):e42009. 
[17] Beijing: United Nations UN Joint United Nations Programme on HIV/AIDS (UNAIDS) [Internet]. 2001 [accessed 5.04.12; Cited April 8, 2012]. Available at:, http://www.unaids.org/en/ media/unaids/contentassets/dataimport/publications/ircpub06/jc941-cuttingedge_en.pdf.

[18] Brazilian Health Ministry. Resposta: experience of the Brazilian AIDS program. Brasilia: Ministry of Health; 2002.

[19] Abdullah AS, Fielding R, Hedley AJ. Travel, sexual behavior, and the risk of contracting sexually transmitted diseases. Hong Kong Med J 1998;4(2):137-44.

[20] Memish ZA, Osoba AO. Sexually transmitted diseases and travel. Int J Antimicrob Agents 2003;21(2):131-4.

[21] McNulty AM, Egan C, Wand H, Donovan B. The behavior and sexual health of young international travelers (backpackers) in Australia. Sex Transm Infect 2010;86(3):247-50.

[22] Ansart S, Hochedez P, Perez L, Bricaire F, Caumes E. Sexually transmitted diseases diagnosed among travelers returning from the tropics. J Travel Med 2009;16(2):79-83.
[23] Cabada MM, Montoya M, Echevarria JI, Verdonck K, Seas C, Gotuzzo E. Sexual behavior in travelers visiting Cuzco. J Travel Med 2003;10(4):214-8.

[24] Thomson MM, Najera R. Travel and the introduction of human immunodeficiency virus type 1 non-B subtype genetic forms into western countries. Clin Infect Dis 2001;32:1732-7.

[25] Martin J, Rieke B, Neppach K, Hillebrandt D, Küpper T. Risk to young volunteers in international social projects. Ann Occup Hyg 2012;56(2):242-52.

[26] Rice B, Gilbart VL, Lawrence J, Smith R, Kall M, Delpech V. Safe travels? HIV transmission among Britons travelling abroad. HIV Med 2012;13(5):315-7.

[27] Benotsch EG, Nettles MA, Wong F, Redmann J, Boschini J, Pinkerton SD, et al. Sexual risk behaviour in men attending Mardi Gras celebrations in New Orleans, Louisiana. J Community Health 2007;32(5):343-56. 